\title{
Hypofractionated stereotactic radiotherapy of limited brain metastases: a single-centre individualized treatment approach
}

\author{
Bettina Märtens, Stefan Janssen, Martin Werner, Jörg Frühauf, Hans Christiansen, Michael Bremer \\ and Diana Steinmann
}

\begin{abstract}
Background: We retrospectively report treatment results of our single-centre experience with hypofractionated stereotactic radiotherapy (hfSRT) of limited brain metastases in primary and recurrence disease situations. Our aim was to find the most effective and safe dose concept.

Methods: From 04/2006 to 12/2010, 75 patients, with 108 intracranial metastases, were treated with hfSRT. 52 newly diagnosed metastases (48\%), without up-front whole brain radiotherapy (WBRT), received hfSRT as a primary treatment. 56 metastases (52\%) received a prior WBRT and were treated in this study in a recurrence situation. Main fractionation concepts used for primary hfSRT were 6-7×5 Gy (61.5\%) and 5x6 Gy (19.2\%), for recurrent hfSRT 7-10x4 Gy (33.9\%) and 5-6x5 Gy (33.9\%).
\end{abstract}

Results: Median overall survival (OS) of all patients summed up to 9.1 months, actuarial 6-and 12-month-OS was 59\% and 35\%, respectively. Median local brain control (LC) was 11.9 months, median distant brain control (DC) 3.9 months and intracranial control (IC) 3.4 months, respectively. Variables with significant influence on OS were Gross Tumour Volume (GTV) $(p=0.019)$, the biological eqivalent dose (calculated on a 2 Gy single dose, EQD2, $a / \beta=10)$ $<$ and $\geq$ median of 39 Gy $(p=0.012)$, extracerebral activity of the primary tumour $(p<0.001)$ and the steroid uptake during hfSRT ( $p=0.03)$. LC was significantly influenced by the EQD2, $\leq$ and $>35$ Gy $(p=0.004)$ in both uni- and multivariate Cox regression analysis. Median LC was 14.9 months for EQD2 >35 Gy and 3.4 months for doses $\leq 35$ Gy, respectively. Early treatment related side effects were usually mild. Nevertheless, patients with a EQD2 $>35$ Gy had higher rates of toxicity (31\%) than $\leq 35$ Gy $(8.3 \%$, p=0.026).

Conclusion: Comparing different dose concepts in hfSRT, a cumulative EQD2 of $\geq 35$ Gy seems to be the most effective concept in patients with primary or recurrent limited brain metastases. Despite higher rates of only mild toxicity, this concept represents a safe treatment option.

Keywords: Brain tumours, hfSRT, SRS, Fractionation

\section{Background}

Cancer patients develop brain metastases in $10-40 \%$ $[1,2]$. The aim of treatment is to provide disease control with a good quality of life, even though prolonged survival may not always be achieved [3]. Whole brain radiotherapy (WBRT) is considered to be the standard treatment option for multiple brain filiae $[4,5]$. Concerns about WBRT achieving only a limited treatment response

\footnotetext{
* Correspondence: Steinmann.Diana@mh-hannover.de

Radiation Oncology, Medical School Hannover, Carl-Neuberg-Str. 1, Hannover 30625, Germany
}

and causing side-effects like cognitive and neurological deficits, and reduced quality of life [6-10] lead us to focus on options like stereotactic radiosurgery (SRS) or hypofractionated stereotactic radiotherapy (hfSRT) in cases of limited brain metastases. SRS is limited by the proximity to critical brain regions, the lesions' dimension and is typically restricted to tumours $\leq 3 \mathrm{~cm}$ diameter $(15 \mathrm{ccm})$ [11]. Large metastases and irregular contrast enhancement have been shown to correlate with an inferior outcome after SRS $[12,13]$ or enhanced side effects $[14,15]$. Different study groups used hfSRT in order to overcome 
limitations of SRS, yielding similar tumour control and providing radiobiological advantages [16-20]. In 2006 we initiated the application of hfSRT whenever highly focussed stereotactic intracranial radiotherapy was indicated but tumour size or localization rendered a single-time treatment impossible.

HfSRT of more than one metastasis was carried out either simultaneously or successively in a primary setting or in a recurrent situation. The aim of this retrospective analysis was to evaluate an efficient and safe dose concept of hfSRT for limited (1-4) brain metastases.

\section{Methods}

\section{Patient characteristics}

Between April 2006 and December 2010, 75 patients with 108 brain metastases were treated with hfSRT and retrospectively analysed. After interdisciplinary discussion a surgical treatment approach had been excluded due to comorbidity, age, or localization of the tumour. Diagnosis of brain metastases was based on pre-treatment magnetic resonance imaging (MRI). Only patients with Karnofsky performance status $\geq 70$ were included. 41 patients (55\%) received a primary definitive hfSRT of 52 newly diagnosed metastases (48\%). 34 patients (45\%) with 56 metastases (52\%) were treated with hfSRT in a recurrence situation. Patient and treatment characteristics are summarized in Table 1 and 2 .

The need of ethical approval is waived because of the retrospective character of the study. Authorization for the use of patient data was given to the authors by the Head of the Departement of Radiooncology of the Medical School in Hannover.

\section{Radiotherapy}

All patients were informed about radiotherapeutic alternatives, in detail. If hfSRT was chosen, repeated MRI scans were conducted after completing radiotherapy, in order to detect early intracranial progress or radiotoxicity. All patients were immobilized using a tight thermoplastic stereotactic head mask. Helical-CT images of $2 \mathrm{~mm}$ slice thickness were fused with axial T1 weighted contrast enhanced MR images. Gross Tumour Volume (GTV) was

Table 1 Patients characteristics

\begin{tabular}{|c|c|c|c|c|c|}
\hline \multirow[b]{2}{*}{ Age } & \multirow[b]{2}{*}{ Median (years), range } & \multicolumn{2}{|c|}{$\begin{array}{l}\text { Total patients } n=75 \\
\text { Primary } n=41\end{array}$} & \multicolumn{2}{|c|}{ Recurrence $n=34$} \\
\hline & & 57.3 & $40.2-79.2$ & 57.7 & $38.4-79.9$ \\
\hline & & $n$ & [\%] & $n$ & [\%] \\
\hline \multirow[t]{2}{*}{ Gender } & male & 20 & 48.8 & 15 & 44.1 \\
\hline & female & 21 & 51.2 & 19 & 55.9 \\
\hline \multirow[t]{6}{*}{ Primary tumour } & Non-small cell lung cancer & 22 & 53.6 & 11 & 32.4 \\
\hline & Breast cancer & 5 & 12.2 & 12 & 35.3 \\
\hline & Malignant melanoma & 6 & 14.6 & 3 & 8.8 \\
\hline & Renal cell carcinoma & 4 & 9.8 & 2 & 5.9 \\
\hline & Small cell lung cancer & 0 & 0 & 5 & 14.7 \\
\hline & Others & 4 & 9.8 & 1 & 2.9 \\
\hline \multirow[t]{3}{*}{ RPA-classification } & 1 & 7 & 17.1 & 13 & 38.2 \\
\hline & 2 & 34 & 82.9 & 21 & 61.8 \\
\hline & 3 & 0 & 0 & 0 & 0 \\
\hline \multirow[t]{3}{*}{ Extracranial tumour status } & in remission & 5 & 12.2 & 11 & 32.4 \\
\hline & detectable, stable disease & 10 & 24.4 & 8 & 23.5 \\
\hline & progressive & 26 & 63.4 & 15 & 44.1 \\
\hline \multirow[t]{4}{*}{ Metastases treated with hfSRT (patients) } & 1 & 32 & 78.0 & 19 & 55.9 \\
\hline & 2 & 7 & 17.1 & 9 & 26.5 \\
\hline & 3 & 2 & 4.9 & 5 & 14.7 \\
\hline & 4 & 0 & 0 & 1 & 2.9 \\
\hline $\begin{array}{l}\text { Time between diagnosis of primary tumour } \\
\text { and brain metastasis }\end{array}$ & Median (months), range & 12.5 & $0-166.4$ & 12.3 & $0-337.7$ \\
\hline $\begin{array}{l}\text { Time between diagnosis of brain metastasis } \\
\text { and start of hfSRT }\end{array}$ & Median (month), range & 1.4 & $0.2-39.9$ & 11.4 & $0.5-37.9$ \\
\hline Intervall between WBRT and start of hfSRT & Median (month), range & 0 & 0 & 12.7 & $0.5-28.8$ \\
\hline
\end{tabular}


Table 2 Treatment characteristics

\begin{tabular}{|c|c|c|c|c|c|c|}
\hline & \multicolumn{2}{|c|}{ Total metastases (108) } & $\begin{array}{l}\text { Primary } \\
\mathrm{m}=52\end{array}$ & Range & $\begin{array}{l}\text { Recurrence } \\
\mathrm{m}=56\end{array}$ & Range \\
\hline GTV & \multicolumn{2}{|c|}{ Median (ccm) } & 1.0 & $0.1-19.0$ & 2.0 & $0.1-29.2$ \\
\hline PTV & \multicolumn{2}{|c|}{ Median (ccm) } & 4.7 & $1.1-41.0$ & 9.2 & $1.6-62.4$ \\
\hline Brain volume treated with $4 \mathrm{~Gy}\left(\mathrm{~V}_{4 \mathrm{~Gy}}\right)$ & \multicolumn{2}{|c|}{ Median (ccm) } & 18.4 & $0-55.3$ & 16.6 & $0-68.7$ \\
\hline Duration of hfSRT & \multicolumn{2}{|c|}{ Median (days) } & 15 & $8-32$ & 16 & $5-23$ \\
\hline \multirow[t]{7}{*}{ Recurrence situation } & \multicolumn{2}{|c|}{ WBRT dose concepts } & & & & [\%] \\
\hline & \multicolumn{2}{|l|}{$-10 \times 3$ Gy } & 0 & & 27 & 48.2 \\
\hline & \multicolumn{2}{|l|}{$-15 \times 2.5 \mathrm{~Gy}$} & 0 & & 11 & 19.7 \\
\hline & \multicolumn{2}{|l|}{$-15 \times 2 \mathrm{~Gy}$} & 0 & & 4 & 7.1 \\
\hline & \multicolumn{2}{|l|}{$-20 \times 2$ Gy } & 0 & & 8 & 14.3 \\
\hline & \multicolumn{2}{|l|}{ - others } & 0 & & 6 & 10.7 \\
\hline & & & $\mathrm{m}$ & {$[\%]$} & $\mathrm{m}$ & [\%] \\
\hline \multirow[t]{7}{*}{ Localization of brain metastases } & \multicolumn{2}{|c|}{ frontal/frontoparietal } & 15 & 28.8 & 13 & 23.2 \\
\hline & \multicolumn{2}{|c|}{ temporal } & 1 & 1.9 & 6 & 10.7 \\
\hline & \multicolumn{2}{|c|}{ parietal/occipital } & 13 & 25.0 & 15 & 26.8 \\
\hline & \multicolumn{2}{|c|}{ central brain } & 7 & 13.5 & 7 & 12.5 \\
\hline & \multicolumn{2}{|l|}{ brainstem } & 3 & 5.8 & 2 & 3.6 \\
\hline & \multicolumn{2}{|l|}{ cerebellum } & 8 & 15.4 & 11 & 19.6 \\
\hline & \multicolumn{2}{|l|}{ others } & 5 & 9.6 & 2 & 3.6 \\
\hline Dose concepts & EQD2 (Gy) & median GTV $(\mathrm{ccm})$ & & & & \\
\hline 10x3 Gy & 33 & 9.29 & 1 & 1.9 & 3 & 5.4 \\
\hline $5 \times 4$ Gy & 23 & 4.00 & & 0.0 & 3 & 5.4 \\
\hline $7 x 4$ Gy & 33 & 4.70 & & 0.0 & 11 & 19.6 \\
\hline $8 \times 4$ Gy & 37 & 2.75 & 2 & 3.8 & 4 & 7.1 \\
\hline $9 \times 4$ Gy & 42 & 5.56 & & 0.0 & 2 & 3.6 \\
\hline 10x4 Gy & 47 & 4.50 & 7 & 13.5 & 2 & 3.6 \\
\hline $4 \times 5$ Gy & 25 & 4.00 & & 0.0 & 1 & 1.8 \\
\hline $5 \times 5$ Gy & 31 & 2.00 & & 0.0 & 5 & 8.9 \\
\hline $6 \times 5$ Gy & 38 & 1.00 & 10 & 19.2 & 14 & 25.0 \\
\hline $7 \times 5$ Gy & 44 & 0.87 & 22 & 42.3 & 4 & 7.1 \\
\hline $5 \times 6$ Gy & 40 & 0.76 & 10 & 19.2 & 7 & 12.5 \\
\hline total & & 1.46 & 52 & 100.0 & 56 & 100.0 \\
\hline
\end{tabular}

defined as the contrast enhancing tumour, a $4 \mathrm{~mm}$ margin in all directions was added for definition of Planning Target Volume (PTV). Oncentra Masterplan Planning System (Nucleotron, Germany, 84 lesions) or the Brainlab iPlan System (Feldkirchen, 24 lesions) was used.

The chosen fractionation scheme depended on the size, number and site of the brain metastases as well as on the 're-irradiation' factor in a recurrent situation. Single doses of 5 to 6 Gy were aimed in primary setting, single lesions, small GTV $(<2 \mathrm{ccm})$ and in uncritical regions. If normal brain volume receiving more than 4. Gy $\left(\mathrm{V}_{4 \mathrm{~Gy}}\right)$ exceeded $23 \mathrm{ccm}$, the single dose was reduced to 4 Gy to prevent toxicity [17]. For recurrence, generally a more restrictive fractionation concept (Equivalent dose in 2 Gy fractions (EQD2 < 40 Gy) was used. Dose concepts and associated mean GTV are summarized in Table 2.

The EQD2 makes different radiation schedules comparable and is calculated with the equation EQD2 $=\mathrm{D} \times$ $([\mathrm{d}+\alpha / \beta] /[2 \mathrm{~Gy}+\alpha / \beta])$, considering the linear-quadratic model. $\mathrm{D}$ is the total dose, $\mathrm{d}$ is the dose per fraction and the $\alpha / \beta$ ratio is an experimentally defined value of tissues. Assuming an $\alpha / \beta$ ratio of 10 Gy for tumour cell kill, the EQD2 of the radiation concepts are 40 Gy (30 Gy in 5 fractions), 44 Gy (35 Gy in 7 fractions) and 47 Gy (40 Gy in 10 fractions), exemplarily (Table 2) [21]. 
Patient positioning was checked with an on-board imaging (IGRT) before irradiation by using a cone-beam CT (XVI, Elekta) and X-ray images (Iview, Elekta) for verification of the isocenter. Radiotherapy was carried out using a Linac with 6 MVX photons in four to six beams, and a multi leaf collimator with a leaf width of $1 \mathrm{~cm}$. For 24 lesions Brain Lab System with individual blends was used.

Between each fraction at least one day treatment interruption was provided.

\section{Follow-up}

Patients were monitored on a regular basis by the treating radiation oncologist. Performance status, neurological symptoms, and steroid uptake were monitored. After a planned period of 6 to 12 weeks the first MRI control was performed. Further follow-up MRI scans were carried out in intervals of $2-3$ months. Treatment failure was considered as occurrence of new or increased contrast enhancement in the irradiated area (with or without increased volumes). Early side effects, i.e. alopecia, fatigue or headache, were scored with the CTC-AE 3.0 scoring system. Late effects ( $>90$ days after hfSRT) were not considered as these could not be analysed systematically due to retrospective data collection.

\section{Statistical analysis}

Analysed endpoints were local control (LC), distant brain control (DC), intracranial control (IC) and overall survival (OS). Local relapse was defined as occurrence of new or increasing contrast enhancement in follow-up MRI in the irradiation area, after involvement of an experienced neuroradiologist. Distant brain failure was defined as any new brain metastases beyond local relapse, intracranial failure as any intracranial progress including local relapse. Survival rates and univariate analysis were calculated by the Kaplan-Meier log-rank test. All events were measured from the first treatment day of hfSRT. The following variables were used: sex, age $(<57.5 y$. vs. $\geq 57.5 y$.), primary (non-small cell lung cancer vs. other), RPA (recursive partitioning analysis) prognostic group (1 vs. 2 ), primary vs. recurrent treatment, GTV $(<2.0$ vs. $\geq 2.0 \mathrm{ccm})$, steroid uptake (yes or no), median $\mathrm{V}_{4 \mathrm{~Gy}}(<16.7 \mathrm{ccm}$ vs. $\geq 16.7 \mathrm{ccm})$, EQD2 ( $\leq 35$ Gy vs. $>35$ Gy), median EQD2 (<39 Gy vs. $\geq 39$ Gy), median time interval between diagnosis of the primary tumour and brain metastases ( $<12.5$ vs. $\geq 12.5$ months). Multivariate Cox Proportional Regression Analysis was performed only with variables significant in the univariate analysis.

T-test of independent samples was used to compare GTV of different dose concepts and to compare toxicity rates. All statistical analysis was performed using IBM
SPSS Statistics 20. A p-value $<0.05$ was considered to be statistically significant.

\section{Results}

\section{Overall survival and influencing factors}

Median OS summed up to 9.1 months with a median follow-up of 9.5 months (range 1.0-50.6 months). Median follow-up of patients being alive until August 2012 ( $\mathrm{n}=5,7 \%$ ) was 36.6 months (range 21.9-50.6 months). Actuarial 6- and 12-months-OS was 59\% and 35\%. Variables with significant influence on OS after multivariate analysis were the extracranial activity of primary tumour $(\mathrm{p}<0.001)$, the steroid uptake $(\mathrm{p}=0.03)$, the GTV $(\mathrm{p}=0.019)$ (Figure 1) and a total dose EQD2 $\geq 39$ Gy $(\mathrm{p}=0.012)$. Detailed OS data is presented in Table 3.

\section{Local and intracranial control}

After a median of 2.2 months (range: 0.3-10.5 months) patients received the first follow-up MRI scan. Two patients $(2.7 \%)$ were lost to follow-up and fourteen patients (18.7\%) died within 90 days (range 13-75 days) of hfSRT and before the first follow-up imaging was carried out. 88 lesions $(81.5 \%)$ were evaluated.

Imaging was done in 56 cases within 40-90 days after the end of hfSRT. 29 metastases (51.8\%) showed a complete remission, $20(35.7 \%)$ a partiell remission and $7(12.5 \%)$ a progress.

Local control in the irradiated area after 6 and 12 months was $73 \%$ and $52 \%$, respectively, median LC was 11.9 months. The EQD2 significantly influenced LC ( $\mathrm{p}=0.004$, multivariate analysis). Median LC was 14.9 months for EQD2 >35 Gy and 3.4 months for doses $\leq 35$ Gy. Actuarial LC rates for biological irradiation

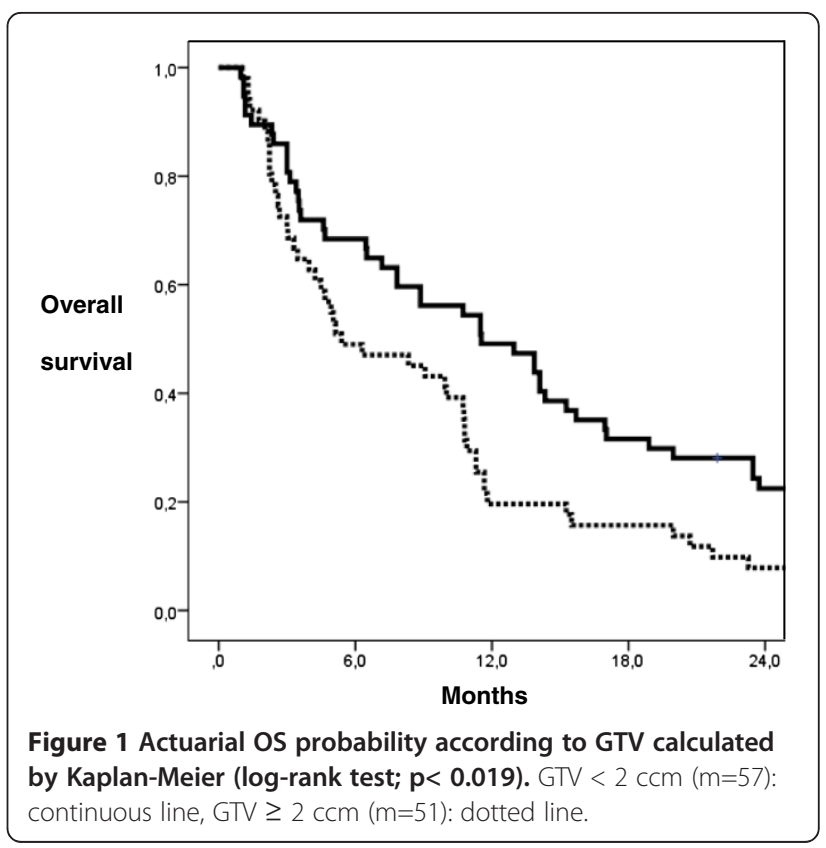


Table 3 Actuarial overall survival according to potential factors and the result of univariate and multivariate analysis

\begin{tabular}{|c|c|c|c|c|c|}
\hline & No. metastases & $\begin{array}{l}\text { 1-year actuarial } \\
\text { OS (\%) }\end{array}$ & $\begin{array}{l}\text { Median } \\
\text { OS (months) }\end{array}$ & $\begin{array}{l}\text { Univariate } \\
p \text { value }\end{array}$ & $\begin{array}{l}\text { Multivariate } \\
p \text { value }\end{array}$ \\
\hline Gender & & & & 0.955 & \\
\hline male & 55 & 35 & 9.9 & & \\
\hline female & 53 & 33 & 9.1 & & \\
\hline Age & & & & 0.777 & \\
\hline < 57.5 years (median) & 54 & 44 & 9.9 & & \\
\hline$\geq 57.5$ years (median) & 54 & 24 & 6.3 & & \\
\hline NSCLC vs. Others & & & & 0.778 & \\
\hline NSCLC & 43 & 40 & 7.2 & & \\
\hline others & 65 & 32 & 10.7 & & \\
\hline RPA & & & & 0.010 & \\
\hline 1 & 36 & 50 & 11.8 & & \\
\hline$\|$ & 72 & 28 & 4.7 & & \\
\hline Extracerebral activity of primary tumor & & & & 0.001 & 0.001 \\
\hline not detectable & 30 & 47 & 11.7 & & \\
\hline stable & 25 & 48 & 10.0 & & \\
\hline progredient & 53 & 23 & 4.0 & & \\
\hline Objective of therapy & & & & 0.217 & \\
\hline primary & 52 & 37 & 8.9 & & \\
\hline recurrence & 56 & 34 & 10.0 & & \\
\hline Steroid uptake & & & & 0.005 & 0.030 \\
\hline yes & 51 & 18 & 5.4 & & \\
\hline no & 57 & 51 & 13.0 & & \\
\hline GTV & & & & 0.004 & 0.019 \\
\hline$<2 \mathrm{ccm}$ & 57 & 49 & 11.5 & & \\
\hline$\geq 2 \mathrm{ccm}$ & 51 & 20 & 5.4 & & \\
\hline EQD2 (35 Gy) & & & & 0.021 & 0.298 \\
\hline$\leq 35$ Gy & 24 & 13 & 3.6 & & \\
\hline$>35 \mathrm{~Gy}$ & 84 & 42 & 10.7 & & \\
\hline EQD2 (median 39 Gy) & & & & 0.009 & 0.012 \\
\hline$<39 \mathrm{~Gy}$ & 54 & 26 & 7.2 & & \\
\hline$\geq 39$ Gy & 54 & 44 & 11.5 & & \\
\hline V4 Gy (median 16.7 ccm) & & & & 0.271 & \\
\hline$<16.7 \mathrm{ccm}$ & 56 & 32 & 7.2 & & \\
\hline$\geq 16.7 \mathrm{ccm}$ & 52 & 38 & 9.1 & & \\
\hline \multicolumn{4}{|c|}{ Time between diagnosis of primary and diagnosis of brain metastases } & 0.092 & \\
\hline$<12.5$ months & 52 & 30 & 9.1 & & \\
\hline$\geq 12.5$ months & 56 & 40 & 8.9 & & \\
\hline
\end{tabular}

doses $>$ and $\leq 35$ Gy were $80 \% / 44 \%$ after 6 months and $57 \% / 22 \%$ after 12 months, respectively (Figure 2). The median EQD2 of $<$ and $\geq 39$ Gy was not a significant factor influencing LC.

LC analysis of different dose concepts showed a 6- and 12-months LC of $90 \% / 66 \%$ for the $6 \times 5$ Gy concept. LC for $5 \times 6$ Gy was $83 \% / 63 \%, 73 \% / 42 \%$ for $7 \times 5$ Gy and $64 \% /$
$21 \%$ for $10 \times 4$ Gy, respectively. Differences in LC were not significant.

Distant brain control (outside the irradiated area) after 6 and 12 months was $51 \%$ and 35\%, median DC was 3.9 months. Fifteen patients with primary treated metastases suffered from a distant brain relapse, four had multiple metastases $(\geq 3)$ and eleven developed limited (1-2) 


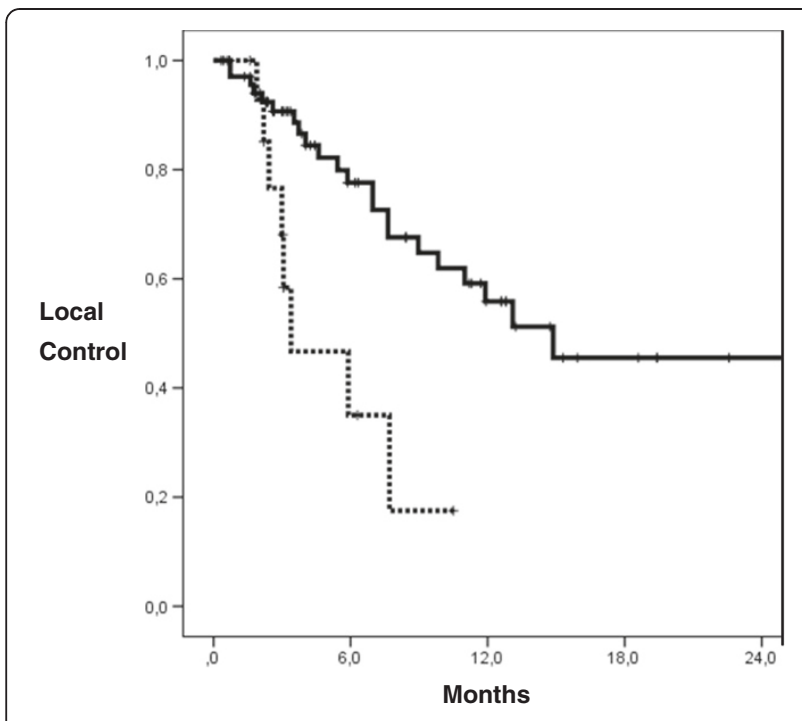

Figure 2 Actuarial LC probability according to EQD2 calculated by Kaplan-Meier (log-rank test; $\mathbf{p}=\mathbf{0 . 0 0 4})$. EQD2 > $35 \mathrm{~Gy}(\mathrm{~m}=73)$ : continuous line, EQD2 $\leq 35$ Gy $(m=15)$ : dotted line.

metastases. Two patients with distant brain relapse were treated with hfSRT, nine with WBRT, one got further chemotherapy and one had a surgical resection. Treatment of two patients was not known.

Intracranial control (includes local and distant brain control) was $41 \%$ and $20 \%$, median being 3.4 months. No other variables with significant influence on DC, IC, LC and OS could be identified.

\section{Survival data of recurrence hfSRT}

In recurrent situations 56 metastases were treated with a median EQD2 of 38 Gy while in comparison 52 metastases in primary situation were treated with a median EQD2 of 44 Gy.

The aspect of primary or recurrence hfSRT did not have a statistically significant influence on OS or on LC. Median OS of primary hfSRT was 8.8 months, while in recurrence situations it was 10 months $(\mathrm{p}=0.217$ in univariate and $\mathrm{p}=0.124$ in multivariate Cox regression analysis). 6- and 12-months-OS-rates for primary hfSRT were $62 \% / 37 \%$ and for recurrence hfSRT they were $57 \% / 34 \%$. 6- and 12 -months-rates of LC, DC and IC for primary hfSRT were $75 \% / 55 \%$, $56 \% / 51 \%$ and $46 \% / 30 \%$ while for recurrence hfSRT they amounted $71 \% / 49 \%, 46 \% / 25 \%$ and $38 \% / 16 \%$, respectively.

\section{Toxicity}

For proper interpretation of toxicity results, we would like to point out, that $36(48.0 \%)$ patients were treated with chemotherapy during the 3-month time period before the start of hfSRT. Furhtermore, it should be considered that 40 patients $(53.3 \%)$ received steroids during radiotherapy. The median dose of dexamethasone at the end of radiotherapy was $4 \mathrm{mg}$ per day.

Only mild early toxicity (CTC-AE v. 3.0 grade 1 ) was observed: alopecia (9 patients), fatigue (8 patients), headache (6 patients), nausea ( 2 patients) or mucositis (2 patients). One patient with hfSRT to four brain metastases, treated with a molecular therapy (Sunitinib) until the start of radiation, showed short term memory loss and amnesic aphasia. Another patient with chemotherapy just until the start of hfSRT suffered from vision disorder.

In only 2 cases out of 24 with a radiation dose EQD2 $\leq 35$ Gy (8.3\%) a toxicity was seen compared to 26 cases out of 84 with an EQD2 >35 Gy (31\%, p=0.026).

The GTV $(<$ and $\geq 2 \mathrm{ccm})$ and the a brain volume treated with 4 Gy $\left(\mathrm{V}_{4 \mathrm{~Gy}}\right)$ ( $<$ and $\geq$ median of $16.7 \mathrm{ccm}$ or $<$ and $\geq 23 \mathrm{ccm}$ ) had no significant influence on toxicity $(29.8 \%$ vs. $21.6 \%, \mathrm{p}=0.328 ; 30.4 \%$ vs. $21.2 \%$, $\mathrm{p}=0.275 ; 31.2 \%$ vs. $17.1 \%, \mathrm{p}=0.149$ ).

One case of radiation necrosis was discussed in the follow-up analysis. This patient with small cell lung carcinoma was initially treated with a prophylactic WBRT with 30 Gy $(15 \times 2$ Gy). After 14 months the MRI showed 3 metastases of the brain, each of them was treated with hfSRT, the cerebellar metastasis was treated with a total dose of 40 Gy $(10 \times 4$ Gy, EQD2 = 47 Gy). This resulted in a cumulative dose of $77 \mathrm{~Gy}$ in the cerebellum. The suspicion of necrosis was raised after a progress of the cerebellar metastasis with additional calcification showing 6 months later. Simultaneously, the patient suffered from cephalgia, emesis, vertigo and motor dysfunction. She died 3 months later after implantation of an Omaya reservoir and subsequent treatment with chemotherapy and steroids.

\section{Discussion}

This study retrospectively analyses therapeutic results in 75 patients treated with hfSRT to limited brain metastases in a primary, or recurrence, situation. Since 2006 we are offering this option to patients who suffer from limited brain metastases and where surgery or SRS is not a suitable treatment option. We applied different dose concepts dependent on primary or recurrence situation, localization and volume of brain lesion. Dose concepts with a total EQD2 >35 Gy achieved best local control rates with acceptable toxicity. 12-months LC rates of $52 \%$ are lower in comparison to other hfSRT studies or SRS probably because we used very different dose concepts [16,22-27].

The aim of our study was to find the most suitable regime with respect to disease control and side effects. Fahrig et al. also compared different dose concepts like 5x6-7 Gy, 7x5 Gy and 10x4 Gy and achieved 12 months OS of $43 \%, 60 \%$ and $67 \%$, respectively [28]. They 
preferred the 10x4 Gy fractionation, depending on the size and localization of the metastases, and detected no adverse side effects. However, a trend towards higher rates of complete remission in patients with brain metastases was seen treated with $5 \times 6-7$ Gy or $7 \times 5$ Gy in comparison with 10x4 Gy [28]. We preferred using restrictive dose concepts (EQD2 < 40 Gy) in patients with prior WBRT as well as in patients with high tumour volume or tumour proxicity to critical structures. The median EQD2 for GTV $<2 \mathrm{ccm}$ was 40 Gy and for GTV $\geq 2 \mathrm{ccm} 38 \mathrm{~Gy}$. The GTV was significantly higher for metastases treated with a single dose of 3-4 Gy (median $4.76 \mathrm{ccm}$ ) than with 5-6 Gy (median $1.00 \mathrm{ccm}, \mathrm{p}<0.001)$. Recent studies yielded $\mathrm{LC}$ rates of $58.6 \%$ after 12 months in mean volumes of $8 \mathrm{ccm}$ (24 Gy in 3 fractions) [22] and $76 \%$ in median volumes of $4.23 \mathrm{ccm}$ ( $5 \times 6$ Gy after prior WBRT, otherwise $5 \times 7$ Gy) [17]. Aoyama et al. found a significant lower tumour control rate for tumours $>3 \mathrm{ccm}$ (35 Gy in 4 fractions) [29]. Nevertheless, above mentioned hfSRT studies included volumes higher than $3 \mathrm{ccm}$ and showed good results.

Conclusions can be drawn from our study results only to a limited extent because of the relatively small number of patients included, it being a monoinstitutional series and the potential risk of selection biases due to the retrospective study design. However, we consider the results to be valuable with regard to the objective of our analysis. Conclusions of our analysis are also limited due to high diversity of dose concepts (Table 2). In our study only $48 \%$ could be classified into dose concepts defined by Fahrig et al. [28]. Therefore, we could not see significant difference for a specific dose concept for LC or OS.

Furthermore, we detected a significant influence of the EQD2 $(\mathrm{p}=0.004)$ on LC $(14.9$ months for doses $>35$ Gy and 3.4 months for doses $\leq 35 \mathrm{~Gy}$ ) in this study.

An EQD2 >35 Gy is associated with better control rates along with higher but acceptable toxcitiy. Therefore, we consider it is most effective for tumour control.

In SRS higher absolute doses (24 Gy) are associated with higher LC (85\%) after 12 months (compared to 45$49 \%$ with $15-18$ Gy) [30]. For brain metastases $\leq 2 \mathrm{ccm}$ SRS studies found that a single time 20 Gy application seems to render superior results $[31,32]$.

Rades et al. achieved higher LC rates with upfront WBRT (77\%) than with SRS alone (49\%), and thereby showed a benefit of up-front WBRT [33].

Half of our patients (45\%) were treated in a recurrence situation after prior WBRT. LC was not significantly different (49\% after 12 months) in comparison to patients who received primary treatment (55\% after 12 months). Lindvall et al. combined WBRT and hfSRT (30 Gy in 10 fractions and 17 Gy in 1-3 fractions) in 11 patients and compared them to 44 patients with hfSRT (40 Gy in 5 fractions) alone. They showed high LC rates of 100\% and $84 \%$ in a short observation time (mean 3.7 months) [19].

Nevertheless, GTV significantly influenced OS in our study $(<2 \mathrm{ccm}$ median 11.5 months $\geq 2 \mathrm{ccm}$ median 5.4 months). Ernst-Stecken et al. defined GTV and PTV volume above $6 \mathrm{ccm}$ and $13 \mathrm{ccm}$ as negative prognostic factor for OS [17].

According to the results of Ernst-Stecken et al. brain volume receiving $>4$ Gy per fraction should not exceed $23 \mathrm{ccm}$ [17]. Takening this into account, overall adverse effects were only mild in our study. None of our patients suffered from seizures classified as a higher grade side effect. In contrast, $11 \%$ of patients suffered of seizures within 3 months after SRS [23].

A recurrence situation after WBRT or hfSRT has not shown a statistically significant influence on LC, IC or OS in our and other studies [22]. Overall survival for hfSRT in primary and recurrence situations was median 8.8 months and 10 months, respectively. The actuarial OS of $35 \%$ one year after treatment with hfSRT is comparable to the reported SRS series (30-50\%) [16,23,2527] and hfSRT studies (25\%) [22]. Different studies compared SRS alone with WBRT plus a SRS boost. The omission of WBRT in the initial management of patients who underwent SRS alone did not compromise survival or intracranial control $[24,27,34,35]$. De Potter et al. [36] achieved a DC at 1 year of $75 \%$. They used $5 \times 6$ Gy as a boost in addition to WBRT. Patients with primary hfSRT treatment in our study achieved a DC of only $51 \%$ after one year and $60 \%$ of them had a WBRT as salvage therapy. Similar DC results of $36 \%$ without up-front WBRT were presented by Narayana et al. [37].

Therefore, up-front WBRT is worth discussing and not simply expendable to avoid neurotoxicity of the normal brain tissue. Regular MR imaging is necessary to detect cerebral progress as soon as possible. Patients with limited brain metastases should be clearly informed about all possible advantages and disadvantages of the different therapy options.

\section{Conclusion}

HfSRT to limited brain metastases is a non invasive therapy in primary and recurrence situations, and provides a reasonable tumour control and survival benefit. A total EQD2 $>35$ Gy is associated with better tumour control rates and with higher but acceptable toxcitiy. Therefore, it is most effective for control of limited brain metastases.

\section{Competing interests}

The authors declare that they have no competing interests. 


\section{Authors' contributions}

MB and DS participated in the design of the study. BM and DS performed the statistical analyses. All authors provided study material and were involved in manuscript writing; they read and approved the final manuscript. BM and DS drafted the manuscript.

\section{Acknowledgement}

Open Access Publication was sponsored by DFG. Research of the last author, DS, was supported by the MHH Equal Opportunities Office. We thank Alan Roberts and Tahera Ahmad for proofreading.

\section{Received: 27 July 2012 Accepted: 23 October 2012}

Published: 25 October 2012

\section{References}

1. Soffietti R, Ruda R, Mutani R: Management of brain metastases. J Neurol 2002, 249(10):1357-1369.

2. Gavrilovic IT, Posner JB: Brain metastases: epidemiology and pathophysiology. J Neurooncol 2005, 75(1):5-14.

3. Jenkinson MD, Haylock B, Shenoy A, Husband D, Javadpour M: Management of cerebral metastasis: evidence-based approach for surgery, stereotactic radiosurgery and radiotherapy. Eur I Cancer 2011 , 47(5):649-655

4. Borgelt B, Gelber R, Kramer S, Brady LW, Chang CH, Davis LW, Perez CA, Hendrickson FR: The palliation of brain metastases: final results of the first two studies by the Radiation Therapy Oncology Group. Int J Radiat Oncol Biol Phys 1980, 6(1):1-9.

5. Feyer P, Sautter-Bihl ML, Budach W, Dunst J, Haase W, Harms W, Sedlmayer F, Souchon R, Wenz F, Sauer R, Breast Cancer Expert Panel of the German Society of Radiation Oncology (DEGRO): DEGRO Practical Guidelines for palliative radiotherapy of breast cancer patients: brain metastases and leptomeningeal carcinomatosis. Strahlenther Onkol 2010, 186(2):63-69.

6. Asai A, Matsutani M, Kohno T, Nakamura O, Tanaka H, Fujimaki T, Funada N, Matsuda T, Nagata K, Takakura K: Subacute brain atrophy after radiation therapy for malignant brain tumor. Cancer 1989, 63(10):1962-1974

7. Murray KJ, Scott C, Zachariah B, Michalski JM, Demas W, Vora NL, Whitton A, Movsas B: Importance of the mini-mental status examination in the treatment of patients with brain metastases: a report from the Radiation Therapy Oncology Group protocol 91-04. Int I Radiat Oncol Biol Phys 2000, 48(1):59-64.

8. Steinmann D, Schafer C, van Oorschot B, Wypior HJ, Bruns F, Bolling T, Sehlen S, Hagg J, Bayerl A, Geinitz H, Hipp M, Vordermark D: Effects of radiotherapy for brain metastases on quality of life (QoL). Prospective pilot study of the DEGRO QoL working party. Strahlenther Onkol 2009, 185(3):190-197.

9. DeAngelis LM, Delattre JY, Posner JB: Radiation-induced dementia in patients cured of brain metastases. Neurology 1989, 39(6):789-796.

10. Welzel G, Fleckenstein K, Schaefer J, Hermann B, Kraus-Tiefenbacher U, Mai SK, Wenz F: Memory function before and after whole brain radiotherapy in patients with and without brain metastases. Int J Radiat Oncol Biol Phys 2008, 72(5):1311-1318.

11. Al-Shamy G, Sawaya R: Management of brain metastases: the indispensable role of surgery. J Neurooncol 2009, 92(3):275-282.

12. Blonigen BJ, Steinmetz RD, Levin L, Lamba MA, Warnick RE, Breneman JC: Irradiated volume as a predictor of brain radionecrosis after linear accelerator stereotactic radiosurgery. Int J Radiat Oncol Biol Phys 2010, 77(4):996-1001.

13. Shiau CY, Sneed PK, Shu HK, Lamborn KR, McDermott MW, Chang S, Nowak P, Petti PL, Smith V, Verhey LJ, Ho M, Park E, Wara WM, Gutin PH, Larson DA: Radiosurgery for brain metastases: relationship of dose and pattern of enhancement to local control. Int I Radiat Oncol Biol Phys 1997, 37(2):375-383

14. Levegrun S, Hof H, Essig M, Schlegel W, Debus J: Radiation-induced changes of brain tissue after radiosurgery in patients with arteriovenous malformations: dose/volume-response relations. Strahlenther Onkol 2004, 180(12):758-767.

15. Voges J, Treuer H, Sturm V, Buchner C, Lehrke R, Kocher M, Staar S, Kuchta J, Muller RP: Risk analysis of linear accelerator radiosurgery. Int I Radiat Oncol Biol Phys 1996, 36(5):1055-1063.

16. Aoki M, Abe Y, Hatayama Y, Kondo H, Basaki K: Clinical outcome of hypofractionated conventional conformation radiotherapy for patients with single and no more than three metastatic brain tumors, with noninvasive fixation of the skull without whole brain irradiation. Int J Radiat Oncol Biol Phys 2006, 64(2):414-418.

17. Ernst-Stecken A, Ganslandt O, Lambrecht U, Sauer R, Grabenbauer G: Phase II trial of hypofractionated stereotactic radiotherapy for brain metastases: results and toxicity. Radiother Oncol 2006, 81(1):18-24.

18. Hall EJ, Brenner DJ: The radiobiology of radiosurgery: rationale for different treatment regimes for AVMs and malignancies. Int I Radiat Oncol Biol Phys 1993, 25(2):381-385.

19. Lindvall P, Bergstrom P, Lofroth PO, Henriksson R, Bergenheim AT: Hypofractionated conformal stereotactic radiotherapy alone or in combination with whole-brain radiotherapy in patients with cerebral metastases. Int J Radiat Oncol Biol Phys 2005, 61(5):1460-1466.

20. Lindvall P, Bergstrom P, Lofroth PO, Tommy Bergenheim A: A comparison between surgical resection in combination with WBRT or hypofractionated stereotactic irradiation in the treatment of solitary brain metastases. Acta Neurochir (Wien) 2009, 151(9):1053-1059

21. Kellerer AM, Rossi HH: The biophysical properties of 3.9-GeV nitrogen ions. VI. Interpretation of results. Radiat Res 1973, 55(3):447-456.

22. Marchetti M, Milanesi I, Falcone C, De Santis M, Fumagalli L, Brait L, Bianchi L, Fariselli L: Hypofractionated stereotactic radiotherapy for oligometastases in the brain: a single-institution experience. Neurol Sci 2011, 32(3):393-399.

23. Meisner J, Meyer A, Polivka B, Karstens JH, Bremer M: Outcome of moderately dosed radiosurgery for limited brain metastases. Report of a single-center experience. Strahlenther Onkol 2010, 186(2):76-81.

24. Rades D, Bohlen G, Pluemer A, Veninga T, Hanssens P, Dunst J, Schild SE: Stereotactic radiosurgery alone versus resection plus whole-brain radiotherapy for 1 or 2 brain metastases in recursive partitioning analysis class 1 and 2 patients. Cancer 2007, 109(12):2515-2521.

25. Nakagawa K, Tago M, Terahara A, Aoki Y, Sasaki T, Kurita H, Shin M, Kawamoto S, Kirino T, Otomo K: A single institutional outcome analysis of Gamma Knife radiosurgery for single or multiple brain metastases. Clin Neurol Neurosurg 2000, 102(4):227-232.

26. Shirato H, Takamura A, Tomita M, Suzuki K, Nishioka T, Isu T, Kato T, Sawamura Y, Miyamachi K, Abe H, Miyasaka K: Stereotactic irradiation without whole-brain irradiation for single brain metastasis. Int I Radiat Oncol Biol Phys 1997, 37(2):385-391.

27. Sneed PK, Lamborn KR, Forstner JM, McDermott MW, Chang S, Park E, Gutin PH, Phillips TL, Wara WM, Larson DA: Radiosurgery for brain metastases: is whole brain radiotherapy necessary? Int J Radiat Oncol Biol Phys 1999, 43(3):549-558.

28. Fahrig A, Ganslandt O, Lambrecht U, Grabenbauer G, Kleinert G, Sauer R, Hamm K: Hypofractionated stereotactic radiotherapy for brain metastases-results from three different dose concepts. Strahlenther Onkol 2007, 183(11):625-630.

29. Aoyama H, Shirato H, Onimaru R, Kagei K, Ikeda J, Ishii N, Sawamura Y, Miyasaka K: Hypofractionated stereotactic radiotherapy alone without whole-brain irradiation for patients with solitary and oligo brain metastasis using noninvasive fixation of the skull. Int J Radiat Oncol Biol Phys 2003, 56(3):793-800.

30. Vogelbaum MA, Angelov L, Lee SY, Li L, Barnett GH, Suh JH: Local control of brain metastases by stereotactic radiosurgery in relation to dose to the tumor margin. J Neurosurg 2006, 104(6):907-912.

31. Shaw E, Scott C, Souhami L, Dinapoli R, Kline R, Loeffler J, Farnan N: Single dose radiosurgical treatment of recurrent previously irradiated primary brain tumors and brain metastases: final report of RTOG protocol 90-05. Int J Radiat Oncol Biol Phys 2000, 47(2):291-298.

32. Shehata MK, Young B, Reid B, Patchell RA, St Clair W, Sims J, Sanders M, Meigooni A, Mohiuddin M, Regine WF: Stereotatic radiosurgery of 468 brain metastases $<$ or $=2 \mathrm{~cm}$ : implications for SRS dose and whole brain radiation therapy. Int I Radiat Oncol Biol Phys 2004, 59(1):87-93.

33. Rades D, Hornung D, Veninga T, Schild SE, Gliemroth J: Single brain metastasis: radiosurgery alone compared with radiosurgery plus up-front whole-brain radiotherapy. Cancer 2011, 118(11):2980-2985.

34. Hasegawa T, Kondziolka D, Flickinger JC, Germanwala A, Lunsford LD: Brain metastases treated with radiosurgery alone: an alternative to whole brain radiotherapy? Neurosurgeny 2003, 52(6):1318-1326. discussion 1326.

35. Sneed PK, Suh JH, Goetsch SJ, Sanghavi SN, Chappell R, Buatti JM, Regine WF, Weltman E, King VJ, Breneman JC, Sperduto PW, Mehta MP: A multi-institutional review of radiosurgery alone vs. radiosurgery with 
whole brain radiotherapy as the initial management of brain metastases. Int J Radiat Oncol Biol Phys 2002, 53(3):519-526.

36. De Potter B, De Meerleer G, De Neve W, Boterberg T, Speleers B, Ost P: Hypofractionated frameless stereotactic intensity-modulated radiotherapy with whole brain radiotherapy for the treatment of 1-3 brain metastases. Neurol Sci 2012, Epub ahead of print.

37. Narayana A, Chang J, Yenice K, Chan K, Lymberis S, Brennan C, Gutin PH: Hypofractionated stereotactic radiotherapy using intensity-modulated radiotherapy in patients with one or two brain metastases. Stereotact Funct Neurosurg 2007, 85(2-3):82-87.

doi:10.1186/1471-2407-12-497

Cite this article as: Märtens et al:: Hypofractionated stereotactic

radiotherapy of limited brain metastases: a single-centre individualized treatment approach. BMC Cancer 2012 12:497.

\section{Submit your next manuscript to BioMed Central and take full advantage of:}

- Convenient online submission

- Thorough peer review

- No space constraints or color figure charges

- Immediate publication on acceptance

- Inclusion in PubMed, CAS, Scopus and Google Scholar

- Research which is freely available for redistribution 